from which one has, taking into account eq. (9),

$$
M>\frac{2 \pi^{2}}{3} N
$$

So there is surely condensation when (11) is not satisfied. It is therefore proved that in the ground state of a lattice gas there is surely a Bose-Einstein condensation at a low density of the particles.

It follows from eq. (1I) that in the ground state of a system of particles having very small radius $(\varepsilon \rightarrow 0, N \rightarrow \infty)$ there is a Bose-Einstein condensation even when the density of the particles is great.

It is a pleasure to thank our friend F. Mighietata for useful discussions.

\title{
Rotational Levels of Odd-Odd Light Deformed Nuclei.
}

\author{
J. PICARD \\ Service de Physique Nuoléaire à Basse Energie, O.E.N. - Saclay
}

A. G. De Prnho

Istituto de Fisica, P.U.O. - Rio de Janeiro

(Nuovo Oimento, $41 \mathrm{~B}, 239(1966))$

In the legend to Fig. 3 the value of $V$ should read $-39 \mathrm{MeV}$ and in that to Fig. 6 it shonld read $-40 \mathrm{MeV}$. In this last figure the two-body force employed is that of ref. $\left({ }^{9}\right)$ and not that of ref. $\left({ }^{8}\right)$. 